\title{
Electronic gearshift assists for two-wheeler
}

\author{
Hamritha S \\ Assistant Professor, Industrial Engineering and Management, \\ Ramaiah Institute of Technology, Bangalore, India. \\ ID: hamritha.shankar@gmail.com
}

\begin{abstract}
In the present world of automotive sector auto-gear transmission is one of the major growth and innovation to the two-wheeler geared vehicles. This gives a platform to throw light on semi-automatic gear transmission, which can be a kit fit on the bike at any stage i.e. before or after sales of bike. In this paper, gear-shifting mechanisms are designed to make the shifting process smoother and accurate. This design makes the gearshift to avoids jerk and gear clashes while shifting and aim to increase the fuel efficiency by shifting at right instant of engine RPM. Hence, solenoids are used to shift the gears by energizing and reenergizing through $12 \mathrm{~V}$ existing battery in the vehicle. Predominant increase by 13 to $18 \%$ of fuel efficiency is observed by on-boarding gearshift assist mechanism in the vehicle. This is also a motivation factor for differently able people who can use this for gear shifting by hand not to depend on foot for shifting.
\end{abstract}

Keywords: Solenoid: Current carrying coils.

\section{INTRODUCTION}

The paper is an investigation and development of an electronic assist gear-shift for the two wheelers. In this regard, effort is made to design and develop a simple solenoid based gear-shift assist for geared bikes. It was also an initiation to help the differently able to ride bikes effortlessly and have controls at fingers. Gear-shift at the right rpm of engine would reduce the fuel consumption and increase the fuel efficiency. Study is also made that the gear position indicator also plays a vital role in increasing the fuel efficiency.

\section{PROCESS FLOW, FABRICATION AND INSTALLATION}

\section{Electrification}

Section The world is progressing towards the electrification and innovation to optimize vehicle performance by reducing fuel consumption and also by reducing $\mathrm{CO}_{2}$ emission. This paper is the step towards the newer world and supporting society with lesser effort mechanism in the vehicles. In this regard, electrical switches are provided for shifting the gear through solenoid and relay are used to manage the flow of current work effectively [1].

Fig. 1 shows the principle of process flow circuit working for this electronic assist for gear shifting mechanism. Limit switch and push switch are used to ensure the circuit is closed and the process is a fool proof system in all the conditions [2]. These switches allows the solenoids to operate at the right moment only after the clutch is applied completely, hence this is a check point for the gear-shift point and this would optimize the process and increase the fuel efficiency of the vehicle [3].

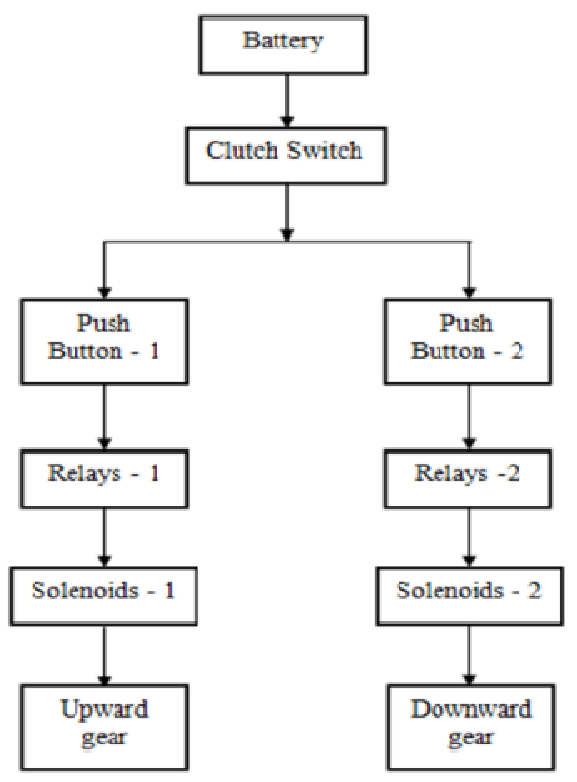

Figure 1. Current flow for electrification 


\section{Mechanical Design:}

It is important that without many changes in the gear lever solenoid to be mounted on the vehicle. Hence, a simple frame with Aluminum plate was fabricated for mounting solenoid on the leg support of the bike. Therefore, two solenoids are used for the arrangement in which one of them will be for down shift and other one for up shift of gears [4].

This fixture consists of two parts namely, primary and secondary plates as shown in the Fig: 2. Primary plate is the one which is in the main plate which supports secondary plates on either side. This should have greater strength to balance the assembly of solenoids and secondary plate. The secondary plates are also important to constraint the movement of solenoid in horizontal direction and these plates are fastened to primary plate. This allows the mechanism to adjust the height of the armature of the solenoid and the distance from center [5].

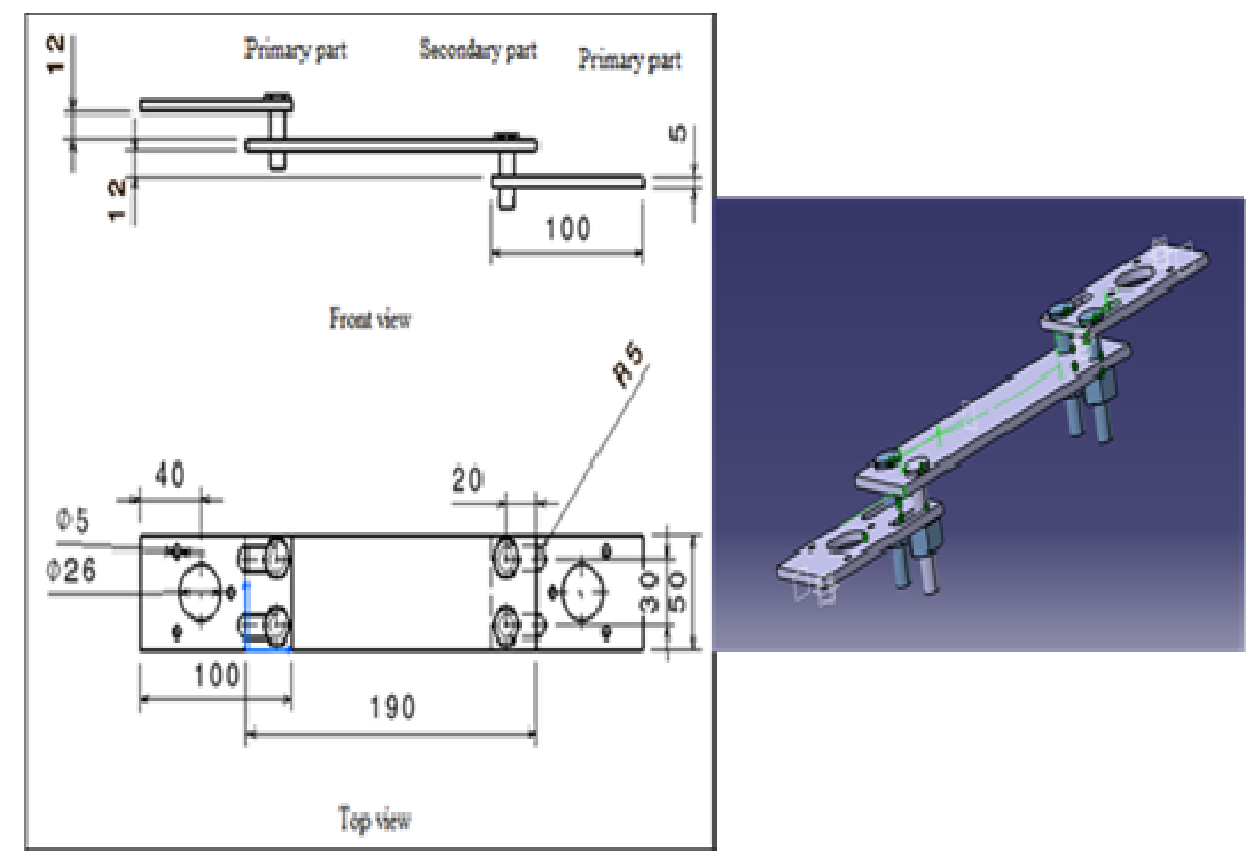

Figure 2. Gear lever plate for mounting solenoid

\section{Installation:}

Installation is an important phase of a project, at most, care was taken and components were installed on to the bike. In this process, clutch input is considered as the primary input and push buttons are secondary inputs for the circuits to trigger the solenoid [6]. These arrangements is made to ensure that the gearshift would happen only after clutch is applied completely. It was observed that gearshift happening at half clutch was damaging the gearbox and inefficient in terms of fuel economy [7] [8].

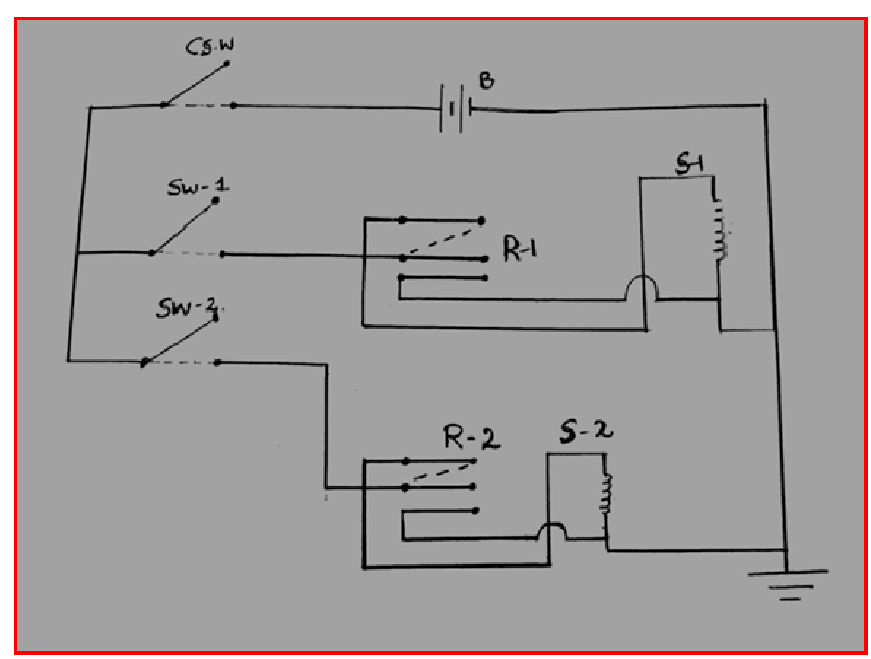

Figure 3. Clutch and solenoid installation 


\section{WORKING}

Considering safety, right time for shifting the gear and improve the fuel economy of the vehicle a simple circuit was developed such that, the clutch is provided with a limit switch(CSW) and also followed by two push switch(SW1,SW2) for shifting the gears to either the higher gear or lower gear number. This clutch limit switch ensured that as safety measure during the gear-shift $100 \%$ clutch was applied and only after that it would trigger the solenoid for shifting the gear [9] [10].

Hence, as the CSW is closed the signals are passed to ensure that SW1 is allowed to operate and solenoid (S1) is triggered. By this, the gear would have shifted from neutral position to 1st gear number. This ensures that gears are not shifted without application of clutch. Similarly, after attaining certain pickup it is necessary to shift the gear at the right moment, taco meter represents that required RPM is achieved and allows the for next gear shift. Hence, during the next shift, it again checks for the input from CSW and ensures SW2 can be operated and when the check point is crossed and solenoid (S2) is allowed to operate and change the gear to the next higher number. These kinds of checkpoints continue on both the directions as based on vehicle speed.

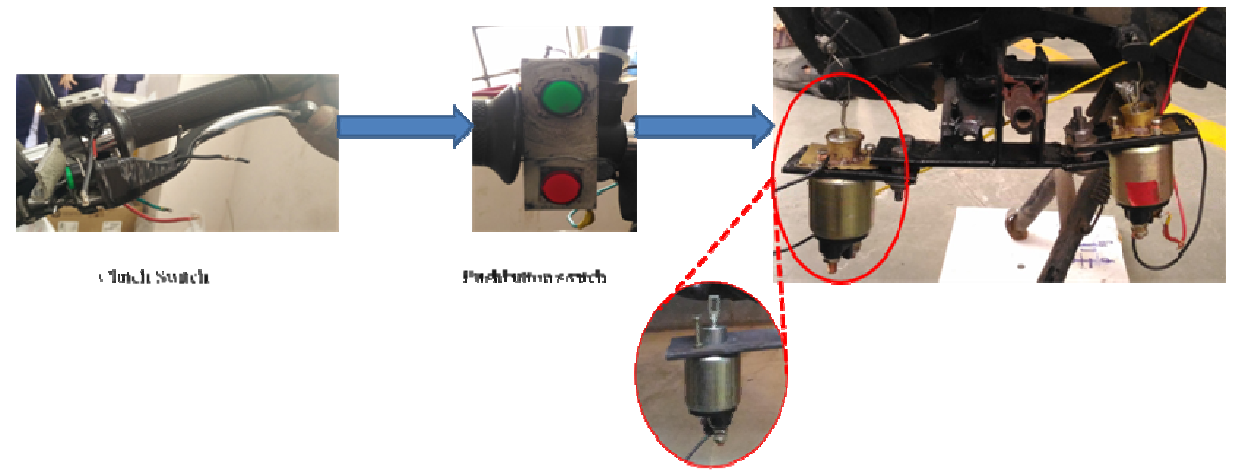

Figure 4 Electrical Circuit

\section{RESULTS AND DISCUSSION}

The results are tabulated for discussion, based on the tests conducted in order to check the performance with respect to fuel economy and to ensure the life of the components on three different days of continuous ride in city condition. It was ensured that fuel consumption was exactly 1lt for every ride on each day. Similarly, base vehicle was also tested before installation of the electronic assist for gear shifting and tabulated for comparison. Results were tabulated for the mileage, based on the fixed consumption of fuel.

As mentioned above, a significant increase in mileage was observed in all the three days ride. On the first day it was around $13 \%$ increase, with this test was continued to check the repeatability and was observed around $18 \%$ on the second day. As there was no consistency on the gain on mileage, it was necessary to check the same on the third day and it was observed that $18 \%$ improvement was recorded. As there was consistency in the percentage gain, the components were removed and investigated for any damage or failure prediction.

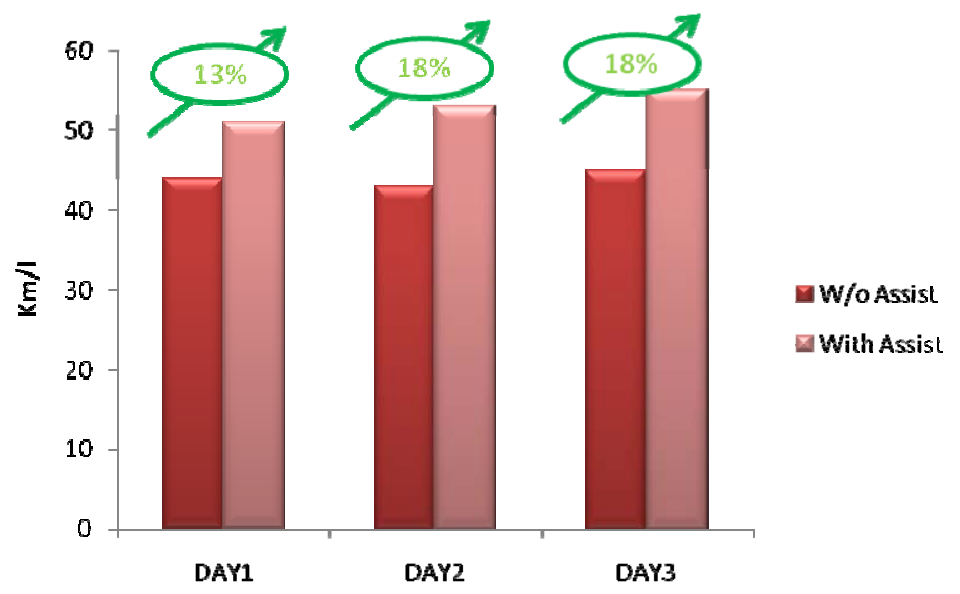

Figure 5. Results on daily basis for 1 lt of fuel 


\section{REFERENCE}

[1] Zongxuan Sun and Kumar Hebbale, "Challenges and Opportunities in Automative Transmission Control", American Control Conference, Portland, OR, 2005: pp 3284-3289.

[2] Lu Xi, Xu Xiangyang and Liu Yanfang, "Simulation of Gear-Shift Algorithm for Automatic Transmission Based on MATLAB”, Published in WCSE. WRI World Congress on Volume: 2, 2009: pp 476-480.

[3] P. Alexander M.E., T. Sudha M.E. and M. Omamageswari M.E., “Automatic Gear Transmission in Two Wheelers Using Embedded System”, International Journal of Advanced Research in Engineering and Technology (IJARET), Volume 3, Issue 2, 2012: pp 164175.

[4] V. Bhargava, "Design and Fabrication of Automatic Gear Transmission System”, 2012.

[5] Darko Stanojevic, Vladimir Spasojevic, Igor Stevanovic and Aleksandar Nedic, “The Contemporary Automatic Gearboxes”, JAES, Volume 11, Issue 2, 2013: pp 89-97.

[6] D.Mangeelal, Ravikanth Raju, K. Nagendra Kumar and P.Amani, “ Button Operated Electro-Magnetic Gear Shifting System”, IJCSIET, Issue 4, Volume 2, 2014: pp 1-11.

[7] Suraj S Raut and D.P.Mali, “Automatic Transmission Gearbox with Centrifugal Clutch”, International Journal of Research in Engineering and Technology (IJRET), Volume 3, Issue 10, 2014: pp 307-309.

[8] S. Vijay Kumar, P. Nithesh Reddy and P. Masoom basha, "Fabrication of Pneumatic Gear Changer", IOSR Journal of Mechanical and Civil Engineering (IOSR-JMCE), Volume 11, Issue 3, 2014: pp 53-63.

[9] Akshyakumar. Puttewar, Pratik Kadu, Narendra Sontakke, Sanket Mahulkar and Sumit Bawaria, "Design and Fabrication of Hand Operated Gear Shifting Mechanism”, IJSRD, Volume 3, Issue 2, 2015: pp689-691.

[10] P. Amuthakkannan, V. Manikandan, S. Muthuram and Pankaj Kumar, "Eccentric Cam Operated Semi Automatic Gear Shifting System for Two Wheeler”, IJAER, Volume 10, Issue 4, 2015: pp 118-124.

\section{Patent}

Hoch, J.A.; Huang, S. Screening methods for the identification of novel antibiotics. U.S. Patent 6,043,045, March 28, 2000.

Mrs. Hamritha S, is an Assistant professor in Department of Industrial Engineering and Management at M S Ramaiah Institute of Technology, Bangalore. Area of intrest is Machine learning, Management topics with data analytics, Material science and process optimization. 